\title{
The prognostic significance of erythrocyte sedimentation rate in COVID-19
}

\author{
Tezcan Kaya ${ }^{1 *}$ (D), Ahmet Nalbant ${ }^{1}$ (D), Gizem Karataş Kilıçcıoğlu ${ }^{10}$, \\ Kübra Tuğba Çayır ${ }^{1}$ (), Selçuk Yaylacı ${ }^{1}$ (1), Ceyhun Varım¹
}

\section{SUMMARY}

OBJECTIVE: There are limited data about the significance of erythrocyte sedimentation rate as a single prognostic parameter for the prognosis and mortality of COVID-19. This study aimed to investigate the diagnostic utility of erythrocyte sedimentation rate as a prognostic factor for the disease severity and mortality in patients with COVID-19.

METHODS: A total of 148 consecutive patients with a confirmed diagnosis of COVID-19 and hospitalized at the intensive care unit or non-the intensive care unit were included in the study. The patients were allocated to groups as severe/critical disease versus nonsevere disease and survivors and nonsurvivors. The prognostic role and predictable values of erythrocyte sedimentation rate were analyzed.

RESULTS: Erythrocyte sedimentation rate was found to be higher among patients with severe/critical disease compared to those with nonsevere disease $(p<0.001)$ and among nonsurvivors compared to survivors $(p<0.001)$. The logistic regression analysis showed that erythrocyte sedimentation rate was an independent parameter for predicting disease severity and mortality. The role of erythrocyte sedimentation rate in the assessment of severity and mortality in patients with COVID-19 was analyzed using the receiver operating characteristic curve and was found to be significant in both. The analyses suggested that the optimum erythrocyte sedimentation rate cutoff point for disease severity and mortality were $52.5 \mathrm{~mm} / \mathrm{h}$ with $65.5 \%$ sensitivity and $76.3 \%$ specificity and $56.5 \mathrm{~mm} / \mathrm{h}$ with $66.7 \%$ sensitivity and $72.5 \%$ specificity.

CONCLUSION: Our results suggest that erythrocyte sedimentation rate was an independent prognostic factor for severity and mortality in patients with COVID-19.

KEYWORDS: Blood sedimentation. COVID-19. Death. Prognosis.

\section{INTRODUCTION}

Coronavirus disease 2019 (COVID-19) caused by severe acute respiratory syndrome coronavirus-2 (SARS-CoV-2) emerged in Wuhan, China, and progressed to a pandemic ${ }^{1}$. SARS$\mathrm{CoV}-2$ can cause a large spectrum of clinical manifestations ${ }^{2,3}$. While COVID-19 may be asymptomatic, it may also lead to severe conditions and death ${ }^{2-4}$.

Many laboratory data, biomarkers, prognostic indices, or scoring systems that could predict the disease severity, prognosis, poor outcomes, and mortality have been reported ${ }^{5-9}$. Most of these prognosis predictors make assessments by using more than one parameter. Erythrocyte sedimentation rate (ESR) is used as a marker that indicates inflammation. ESR was reported to be able to predict the disease activity and prognosis in some other disorders ${ }^{10-12}$. There are few studies available evaluating ESR as a single predictor of the prognosis and mortality in COVID-19 patients. This study aimed to assess the association between ESR and the disease severity and mortality in patients with COVID-19.

\footnotetext{
'Sakarya University Faculty of Medicine, Department of Internal Medicine - Sakarya, Turkey.

*Corresponding author: tezcankaya@gmail.com, tezcan@sakarya.edu.tr

Conflicts of interest: the authors declare there are no conflicts of interest. Funding: none.

Received on June 29, 2021. Accepted on August 01, 2021.
} 


\section{METHODS}

Consecutive patients above 18 years of age who had been hospitalized at the local University Training and Research Hospital between February 1, 2021, and March 31, 2021, with the diagnosis of COVID-19 were included in this retrospective cohort study. The diagnosis of COVID-19 was confirmed with a reverse transcriptase polymerase chain reaction (RT-PCR) test of the nasopharyngeal/oropharyngeal swab. Patients who had malignancy, pregnancy, sepsis, bacterial infection, chronic infection, autoimmune disorder, rheumatic disease, and hematological disorder were excluded from the study. The demographic characteristics, comorbid conditions, and clinical and laboratory data of the patients were collected from the hospital data management system.

The patients were divided into two groups as those with severe/critical disease and nonsevere disease. The diagnosis of the disease severity was made according to the World Health Organization severity definitions ${ }^{4}$. While patients with severe/critical disease were followed up at the intensive care unit (ICU), patients with nonsevere disease were followed up at non-ICU. In addition, patients who survived and died constituted the other two groups. ESR and other laboratory data on admission (to ICU or non-ICU) were recorded. ESR measurement $(\mathrm{mm} / \mathrm{h})$ was made using a fully automated ESR analyzer, and the other laboratory tests were carried out using routine methods. The reference value for ESR was $0-20 \mathrm{~mm} / \mathrm{h}$ for males and $30 \mathrm{~mm} / \mathrm{h}$ for females. The data of the groups were compared. The difference of ESR according to groups and the role in the prediction of the disease severity and mortality were assessed. This study was approved by the local University Ethics Committee (no: E-71522473-050.01.04-6064).

\section{Statistical analysis}

Descriptive analyses of the variables were expressed as mean $\pm S D$ in normal distributions, categorical data were given as numbers and percentages, and parameters with abnormal distribution were expressed as the median of the 25 th-75th percentile. The comparison of difference between the groups was made by chi-square test, independent samples $t$-test, and MannWhitney U test. Pearson correlation analysis was used for correlation between ESR and other parameters. Receiver operating curve (ROC) analysis was used to calculate ESR with the required cutoff values to distinguish disease severity and mortality with maximum sensitivity and specificity. The variables predicting disease severity and mortality were determined by binary logistic regression analysis. The significance value was accepted as $\mathrm{p}<0.05$. The SPSS version 20.0 package program was used in the analyses.

\section{RESULTS}

Of the 148 patients, 81 were female and 67 were male, and the mean age was $63.2 \pm 16.9$ years. While $67(45.27 \%)$ had severe/critical disease, 81 (54.73\%) had nonsevere disease. The mean age of the patients with severe/critical disease was higher $(\mathrm{p}<0.001)$. The median ESR was statistically significantly higher in patients with severe/critical disease (66.5 versus $35.5, \mathrm{p}<0.001)$. The comparison results of the demographics and clinical characteristics between patients with severe/ critical disease and nonsevere disease are provided in Table 1. In addition, white blood cell (WBC) count, neutrophil count, prothrombin time (PT), D-dimer, ferritin, lactate dehydrogenase (LDH), C-reactive protein (CRP), procalcitonin, and fibrinogen were also significantly higher in patients with severe/ critical disease (Table 1). Forty-two (28.38\%) patients had died. The mean age of nonsurvivors was significantly higher $(\mathrm{p}<0.001)$. ESR was statistically significantly higher among nonsurvivors $(69.5$ versus $39, \mathrm{p}<0.001)$. The comparison results of the patients' demographics and the clinical characteristics between survival and death are summarized in Table 2. Furthermore, the WBC count, neutrophil count, D-dimer, ferritin, aspartate transaminase (AST), LDH, CRP, procalcitonin, troponin, and lactate were significantly higher among nonsurvivors (Table 2).

There was a significant positive correlation between ESR and the WBC count, neutrophil count, CRP, procalcitonin, ferritin, and fibrinogen ( $0.197, \mathrm{p}=0.021 ; \mathrm{r} 0.274, \mathrm{p}=0.001$; r $0.496, \mathrm{p}<0.001 ; \mathrm{r} 0.265, \mathrm{p}=0.002$; r 0.386, $\mathrm{p}<0.001$, and r $0.38, \mathrm{p}<0.001$, respectively). The binary logistic regression analysis showed that ESR was an independent parameter for predicting the disease severity (OR 1.035, 95\%CI 1.019$1.051, \mathrm{p}<0.001)$ and mortality (OR 1.030, 95\%CI 1.0131.046). The role of ESR on the assessment of COVID-19 severity and mortality was analyzed using the ROC curve and was found to be significant in both (AUC 0.741; $<<0.001$, 95\%CI 0.657-0.826 and AUC 0.715; p<0.001, 95\%CI $0.715-0.047$; Figure 1). Analyses suggested that the optimum ESR cutoff points for the disease severity and mortality were $52.5 \mathrm{~mm} / \mathrm{h}$ with $65.5 \%$ sensitivity and $76.3 \%$ specificity and $56.5 \mathrm{~mm} / \mathrm{h}$ with $66.7 \%$ sensitivity and $72.5 \%$ specificity, respectively.

\section{DISCUSSION}

The present study has revealed that ESR as a single parameter may predict the disease severity and mortality in patients with COVID-19. The optimum cutoff value of ESR by ROC analysis was $52.5 \mathrm{~mm} / \mathrm{h}$, which resulted in $65.5 \%$ sensitivity and $76.3 \%$ specificity for predicting severe/critical COVID-19. 
Table 1. Comparison of demographics and clinical characteristics between patients with severe/critical disease and the nonsevere disease.

\begin{tabular}{|c|c|c|c|}
\hline & $\begin{array}{l}\text { Patients with severe/ } \\
\text { critical disease }(n=67)\end{array}$ & $\begin{array}{l}\text { Patients with nonsevere } \\
\text { disease }(n=81)\end{array}$ & p-value \\
\hline Age (years) & $70.5 \pm 12.6$ & $57.3 \pm 17.8$ & $<0.001$ \\
\hline Gender (male/female) & $27 / 40$ & $40 / 41$ & 0.269 \\
\hline Diabetes, n (\%) & $25(37.3)$ & $19(23.5)$ & 0.098 \\
\hline Hypertension, n (\%) & $29(43.3)$ & $38(46.9)$ & 0.659 \\
\hline CHD, n (\%) & $10(14.9)$ & $3(3.7)$ & 0.035 \\
\hline COPD, n (\%) & $4(6)$ & $2(2,5)$ & 0.255 \\
\hline Asthma, n (\%) & $6(9)$ & $4(4.9)$ & 0.260 \\
\hline Heart failure, n (\%) & $10(14.9)$ & $3(3.7)$ & 0.017 \\
\hline $\mathrm{WBC}, \mathrm{K} / \mu \mathrm{L}$ & $8150(5940-11000)$ & $5340(4580-6905)$ & $<0.001$ \\
\hline 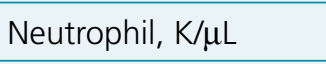 & 5835 (4487-9107) & $3500(2565-4850)$ & $<0.001$ \\
\hline Lymphocyte, $\mathrm{K} / \mu \mathrm{L}$ & $784(511-1212)$ & $1300(900-1710)$ & $<0.001$ \\
\hline Hemoglobin, $\mathrm{g} / \mathrm{dL}$ & $12.5 \pm 1.5$ & $12.5 \pm 1.3$ & 0.823 \\
\hline Platelet, $\mathrm{K} / \mu \mathrm{L}$ & $199(147-259)$ & $179(146-216)$ & 0.143 \\
\hline Prothrombin time, s & $13.4(12.5-14.5)$ & $12.5(11.5-13.5)$ & $<0.001$ \\
\hline D-Dimer ng/mL & $1300(826-2130)$ & $435(220-832)$ & $<0.001$ \\
\hline Ferritin, $\mu \mathrm{g} / \mathrm{L}$ & 607 (380-1438) & $207(71-390)$ & $<0.001$ \\
\hline AST, U/L & $44(29-66)$ & $29(21-37)$ & $<0.001$ \\
\hline Albumin, $\mathrm{g} / \mathrm{dL}$ & $3 \pm 0.4$ & $3.5 \pm 0.7$ & $<0.001$ \\
\hline $\mathrm{LDH}, \mathrm{U} / \mathrm{L}$ & $448(368-572)$ & $257(205-325)$ & $<0.001$ \\
\hline CRP, mg/L & $114(63-172)$ & $19(6.4-63)$ & $<0.001$ \\
\hline Procalcitonin, ng/mL & $0.24(0.12-0.58)$ & $0.05(0.03-0.17)$ & $<0.001$ \\
\hline $\mathrm{ESR}, \mathrm{mm} / \mathrm{h}$ & $66.5(47-73)$ & $35.5(22-52)$ & $<0.001$ \\
\hline Fibrinogen, mg/dL & $409(343-472)$ & $324(302-402)$ & 0.002 \\
\hline Creatine kinase, U/L & $105(68--279)$ & $76(44-136)$ & 0.012 \\
\hline
\end{tabular}

CHD: coronary heart disease; COPD: chronic obstructive pulmonary disease; WBC: white blood cell; aPTT: activated partial thromboplastin time; AST: aspartate transaminase; ALT: alanine transaminase; LDH: lactate dehydrogenase; CRP: C-reactive protein; ESR: erythrocyte sedimentation rate.

Similarly, the suggested cutoff value of ESR by the ROC analysis was $56.5 \mathrm{~mm} / \mathrm{h}$, which resulted in $66.7 \%$ sensitivity and $72.5 \%$ specificity for predicting death in COVID-19.

Some scoring systems that include many parameters have been investigated to determine the severity and mortality rate $^{7,13-15}$. Liang et al. ${ }^{7}$ have reported the COVID-GRAM risk score, which is composed of 10 parameters including chest radiographic abnormality, age, hemoptysis, dyspnea, unconsciousness, the number of comorbidities, cancer history, neutrophil-to-lymphocyte ratio, $\mathrm{LDH}$, and direct bilirubin as a predictor of the progression to critical illness. Boero et al. ${ }^{13}$ revealed that the COVID-19 Worsening Score (COWS), which uses the combination of COVID-GRAM score variables and lung ultrasound score, may determine the patients who need ICU care. In another study, the National Early Warning Score 2 (NEWS 2) was found to be able to predict critical COVID19 patients ${ }^{14,15}$. NEWS 2 score includes respiratory rate, oxygen saturation, need for supplemental oxygen, body temperature, blood pressure, heart rate, the level of consciousness, and new confusion variables ${ }^{14}$. The disadvantage of these scoring systems is predicting the prognosis using many parameters. On the other hand, this study revealed that examination of 
Table 2. Comparison of demographics and clinical characteristics of COVID-19 patients between survival and death.

\begin{tabular}{|c|c|c|c|}
\hline & Survival $(n=106)$ & Death $(n=42)$ & p-value \\
\hline Age (years) & $59.8 \pm 17.6$ & $72.1 \pm 11$ & $<0.001$ \\
\hline Gender (male/female) & $56 / 50$ & $25 / 17$ & 0.579 \\
\hline Diabetes, n (\%) & $29(27.4)$ & $15(35.7)$ & 0.422 \\
\hline Hypertension, n (\%) & $50(47.2)$ & $17(40.5)$ & 0.579 \\
\hline CHD, n (\%) & $14(13.2)$ & $11(26.2)$ & 0.097 \\
\hline COPD, n (\%) & $3(2.8)$ & $3(7.1)$ & 0.223 \\
\hline Asthma, n (\%) & $7(6.6)$ & $3(7.1)$ & 0.578 \\
\hline Heart failure, n (\%) & $9(8.5)$ & $4(9.5)$ & 0.532 \\
\hline $\mathrm{WBC}, \mathrm{K} / \mu \mathrm{L}$ & 6000 (4895-8000) & $8510(5627-12450)$ & $<0.001$ \\
\hline Neutrophil, $\mathrm{K} / \mu \mathrm{L}$ & $4100(2725-5635)$ & 6345 (4210-9662) & $<0.001$ \\
\hline Lymphocyte, $\mathrm{K} / \mu \mathrm{L}$ & $1220(878-1605)$ & 662 (469-1055) & $<0.001$ \\
\hline Hemoglobin, g/dL & $12.6 \pm 1.4$ & $12.3 \pm 1.5$ & 0.215 \\
\hline Platelet, $\mathrm{K} / \mu \mathrm{L}$ & $183(150-237)$ & $187(142-236)$ & 0.990 \\
\hline Prothrombin time, s & $13.2 \pm 6.1$ & $13.8 \pm 1.9$ & 0.001 \\
\hline D-Dimer ug FEU/L & $561(240-1252)$ & $1515(884-2192)$ & $<0.001$ \\
\hline Ferritin, $\mu \mathrm{g} / \mathrm{L}$ & $267(90-653)$ & $576(328-1438)$ & $<0.001$ \\
\hline AST, U/L & $31(22-41)$ & $47(28-78)$ & 0.002 \\
\hline Albumin, g/dL & $3.37 \pm 0.66$ & $2.91 \pm 0.44$ & $<0.001$ \\
\hline $\mathrm{LDH}, \mathrm{U} / \mathrm{L}$ & $289(223-390)$ & $451(357-586)$ & $<0.001$ \\
\hline $\mathrm{CRP}, \mathrm{mg} / \mathrm{L}$ & $37(10-92)$ & $128(72-174)$ & $<0.001$ \\
\hline Procalcitonin, ng/mL & $0.06(0.03-0.20)$ & $0.32(0.18-0.82)$ & $<0.001$ \\
\hline $\mathrm{ESR}, \mathrm{mm} / \mathrm{h}$ & $39(22.7-58.2)$ & $69.5(48-72.7)$ & $<0.001$ \\
\hline Fibrinogen, mg/dL & $348(302-426)$ & $417(354-472)$ & 0.053 \\
\hline Creatine kinase, U/L & $87(55-142)$ & $112(61-295)$ & 0.012 \\
\hline Troponin, ng/L & $5.4(2.9-12)$ & $27.5(11.4-83.9)$ & $<0.001$ \\
\hline Lactate, mmol/L & $1.6(1.2-2)$ & $1.9(1.6-2.3)$ & 0.001 \\
\hline
\end{tabular}

CHD: coronary heart disease; COPD: chronic obstructive pulmonary disease; WBC: white blood cell; APTT: activated partial thromboplastin time; AST: aspartate transaminase; ALT: alanine transaminase; LDH: lactate dehydrogenase; CRP: C-reactive protein; ESR: erythrocyte sedimentation rate.

the ESR alone is sufficient for the prediction of the prognosis of COVID-19.

There are few studies focusing on the relationship between COVID-19 and ESR. Pu et al. ${ }^{16}$ reported in a recent COVID-19 case that ESR remained elevated for a long time and, therefore, they could not determine any other reason to explain the high ESR levels. In some studies, ESR was evaluated together with other parameters when investigating the disease severity and prognosis markers ${ }^{17-20}$. However, no cutoff value was reported for ESR as a predictor of disease severity and mortality until our study.
A review by Xie et al. ${ }^{18}$, including the data of 16,526 COVID-19 patients, evaluated the characteristics that predict progression and reported elevated ESR in $72.2 \%$ of the patients. In the meta-analysis of Zeng et al. ${ }^{17}$, CRP, procalcitonin, interleukin-6 (IL-6), ESR, and ferritin were found to be higher in severe COVID-19 patients. In a systematic review and meta-analysis of Mahat et al. ${ }^{20}$, CRP, ESR, procalcitonin, IL-6, IL-10, IL-2R, serum amyloid A, and the neutrophil-to-lymphocyte ratio were found to be significantly higher in severe COVID-19 patients. 


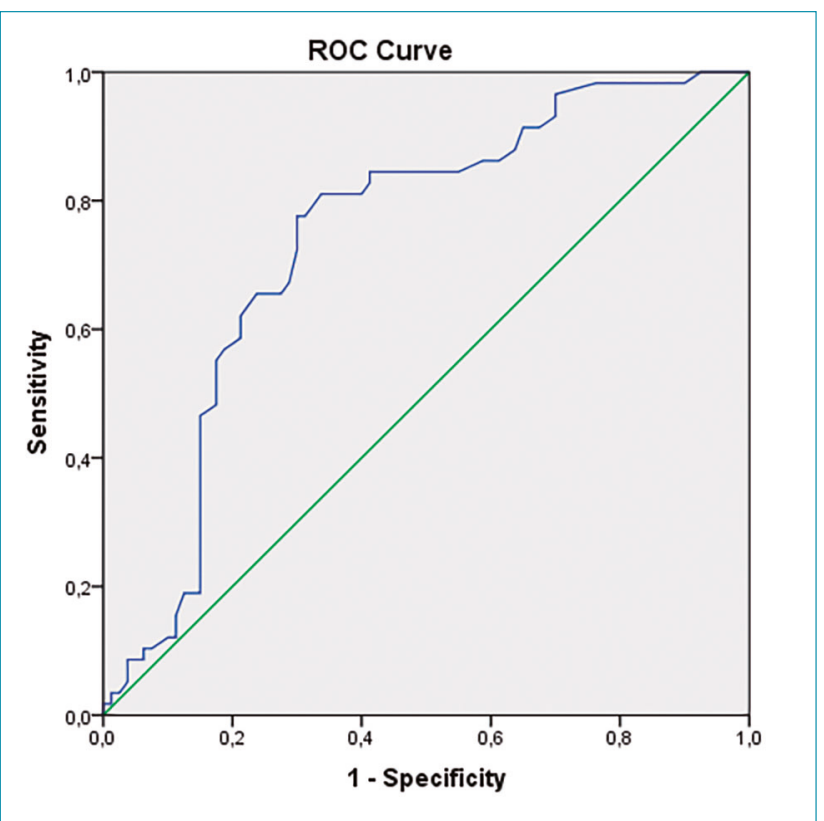

Figure 1. Receiver operating characteristic analysis showing the power of erythrocyte sedimentation rate to predict the disease severity (need for intensive care unit).

\section{CONCLUSIONS}

In this study, we observed that ESR as a single parameter is a valuable biomarker that may predict the disease severity and mortality. In addition, ESR is significantly correlated with the WBC, neutrophil, lymphocyte, CRP, procalcitonin, AST, albumin, D-dimer, and ferritin, which were shown to be significant prognostic markers for COVID-19.

\section{AUTHORS' CONTRIBUTION}

TK: Conceptualization, Data curation, Formal analysis, Project administration, Writing - original draft, Writing - review \& editing. AN: Conceptualization, Data curation, Formal analysis, Project administration, Writing - original draft, Writing - review \& editing. GKK: Conceptualization, Writing - original draft, Writing - review \& editing. KTÇ: Conceptualization, Writing original draft, Writing - review \& editing. SY: Conceptualization, Formal analysis, Writing - original draft, Writing - review \& editing. CV: Conceptualization, Formal analysis, Writing- original draft, Writing - review \& editing.

\section{REFERENCES}

1. Chen N, Zhou M, Dong X, Qu J, Gong F, Han Y, et al. Epidemiological and clinical characteristics of 99 cases of 2019 novel coronavirus pneumonia in Wuhan, China: a descriptive study. The Lancet. 2020;15(395):507-13. https:// doi.org/10.1016/S0140-6736(20)30211-7

2. The Novel Coronavirus Pneumonia Emergency Response Epidemiology Team. The epidemiological characteristics of an outbreak of 2019 novel Coronavirus diseases (COVID-19). China CDC Weekly. 2020;2:113-22. https://doi.org/10.46234/ ccdcw2020.032

3. Mehta AA, Haridas N, Belgundi P, Jose WM. A systematic review of clinical and laboratory parameters associated with increased severity among COVID-19 patients. Diabetes Metab Syndr. 2021;15(2):535-41. https://doi.org/10.1016/j. dsx.2021.02.020

4. World Health Organization. COVID-19 clinical management: living guidance. Geneva: World Health Organization; 2020. [cited on Jan. 6, 2021]. Available from: https://www.who.int/ publications/i/item/WHO-2019-nCoV-clinical-2021-1

5. Pilotto A, Azzini M, Cella A, Cenderello G, Castagna A, Pilotto $A$, et al. Italian Geriatric Society Hospital and Community (SIGOT) study group. The multidimensional prognostic index (MPI) for the prognostic stratification of older inpatients with COVID-19: a multicenter prospective observational cohort study. Arch Gerontol Geriatr. 2021;95:104415. https://doi. org/10.1016/j.archger.2021.104415

6. Li J, Wang L, Liu C, Wang Z, Lin Y, Dong X, et al. Exploration of prognostic factors for critical COVID-19 patients using a nomogram model. Sci Rep. 2021;11:8192. https://doi. org/10.1038/s41598-021-87373-x

7. Liang W, Liang H, Ou L, Chen B, Chen A, Li C, et al. Development and validation of a clinical risk score to predict the occurrence of critical illness in hospitalized patients with COVID-19. JAMA Intern Med. 2020;180(8):1081-9. https://doi.org/10.1001/ jamainternmed.2020.2033

8. Simadibrata DM, Calvin J, Wijaya AD, Ibrahim NAA. Neutrophilto-lymphocyte ratio on admission to predict the severity and mortality of COVID-19 patients: a meta-analysis. Am J Emerg Med. 2021;42:60-9. https://doi.org/10.1016/j.ajem.2021.01.006

9. Mei J, Hu W, Chen Q, Li C, Chen Z, Fan Y, et al. Development and external validation of a COVID-19 mortality risk prediction algorithm: a multicentre retrospective cohort study. BMJ Open. 2020;10(12):e044028. https://doi.org/10.1136/bmjopen2020-044028

10. Park G, Song SY, Ahn JH, Kim WL, Lee JS, Jeong SY, et al. The pretreatment erythrocyte sedimentation rate predicts survival outcomes after surgery and adjuvant radiotherapy for extremity soft tissue sarcoma. Radiat Oncol. 2019;14(1):116. https://doi. org/10.1186/s13014-019-1331-z

11. Stojan G, Fang H, Magder L, Petri M. Erythrocyte sedimentation rate is a predictor of renal and overall SLE disease activity. Lupus. 2013;22(8):827-34. https://doi.org/10.1177/0961203313492578

12. Wu S, Zhou Y, Hua HY, Zhang Y, Zhu WY, Wang ZQ, et al. Inflammation marker ESR is effective in predicting outcome of diffuse large B-cell lymphoma. BMC Cancer. 2018;18(1):997. https://doi.org/10.1186/s12885-018-4914-4 
13. Boero E, Rovida S, Schreiber A, Berchialla P, Charrier L, Cravino MM, et al. The COVID-19 Worsening Score (COWS)-a predictive bedside tool for critical illness. Echocardiography. 2021;38(2):207-16. https://doi.org/10.1111/echo.14962

14. Gidari A, Socio GV, Sabbatini S, Francisci D. Predictive value of national early warning score 2 (NEWS2) for intensive care unit admission in patients with SARS-CoV-2 infection. Infect Dis (Lond). 2020;52(10):698-704. https://doi.org/10.1080/2 3744235.2020 .1784457

15. Socio GV, Gidari A, Sicari F, Palumbo M, Francisci D. National Early Warning Score 2 (NEWS2) better predicts critical Coronavirus Disease 2019 (COVID-19) illness than COVID-GRAM, a multi-centre study. Infection. 2021;49(5):1033-8. https://doi. org/10.1007/s15010-021-01620-x

16. Pu SL, Zhang XY, Liu DS, Ye BN, Li JQ. Unexplained elevation of erythrocyte sedimentation rate in a patient recovering from COVID-19: a case report. World J Clin Cases. 2021;9(6):1394401. https://doi.org/10.12998/wjcc.v9.i6.1394
17. Zeng F, Huang Y, Guo Y, Yin M, Chen X, Xiao L, et al. Association of inflammatory markers with the severity of COVID-19: a meta-analysis. Int J Infect Dis. 2020;96:467-74. https://doi. org/10.1016/j.ijid.2020.05.055

18. Xie J, Wang Q, Xu Y, Zhang T, Chen L, Zuo X, et al. Clinical characteristics, laboratory abnormalities and $\mathrm{CT}$ findings of COVID-19 patients and risk factors of severe disease: a systematic review and meta-analysis. Ann Palliat Med. 2021;10:1928-49. https://doi.org/10.21037/apm-20-1863

19. Ji P, Zhu J, Zhong Z, Li H, Pang J, Li B, Zhang J. Association of elevated inflammatory markers and severe COVID-19: a meta-analysis. Medicine (Baltimore). 2020;99(47):e23315. https://doi.org/10.1097/MD.0000000000023315

20. Mahat RK, Panda S, Rathore V, Swain S, Yadav L, Sah SP. The dynamics of inflammatory markers in coronavirus disease-2019 (COVID-19) patients: a systematic review and meta-analysis. Clin Epidemiol Glob Health. 2021;11:100727. https://doi. org/10.1016/j.cegh.2021.100727 